\title{
Clinical prediction rule for delayed hemothorax after minor thoracic injury: a multicentre derivation and validation study
}

\author{
Marcel Émond MD MSc, Chantal Guimont MD PhD, Jean-Marc Chauny MD MSc, \\ Raoul Daoust MD MSc, Éric Bergeron MD MSc, Laurent Vanier MD PhD, Lynne Moore PhD, \\ Miville Plourde MD MSc, Batomen Kuimi MSc, Valérie Boucher BA, Nadine Allain-Boulé MBA, \\ Natalie Le Sage MD PhD
}

\section{Abstract}

Background: About $75 \%$ of patients with minor thoracic injury are discharged after an emergency department visit. However, complications such as delayed hemothorax can occur. We sought to derive and validate a clinical decision rule to predict hemothorax in patients discharged from the emergency department.

Methods: We conducted a 6-year prospective cohort study in 4 university-affiliated emergency departments. Patients aged 16 years or older presenting with a minor thoracic injury were assessed at 5 time points (initial visit and 7, 14, 30 and $90 \mathrm{~d}$ after the injury). Radiologists' reports were reviewed for the presence of hemothorax. We used log-binomial regression models to identify predictors of hemothorax.

Results: A total of 1382 patients were included: 830 in the derivation phase and 552 in the validation phase. Of these, 151 (10.9\%) had hemothorax at the 14-day follow-up. Patients 65 years of age or older represented $25.3 \%(210 / 830)$ and $23.7 \%$ (131/552) of the derivation and validation cohorts, respectively. The final clinical decision rule included a combination of age (> $70 \mathrm{yr}, 2$ points; 45-70 yr, 1 point), fracture of any high to mid thorax rib (ribs 3-9, 2 points) and presence of 3 or more rib fractures (1 point). Twenty $(30.8 \%)$ of the 65 high-risk patients (score $\geq 4$ ) experienced hemothorax during the follow-up period. The clinical decision rule had a high specificity $(90.7 \%$, 95\% confidence interval $87.7 \%-93.1 \%)$ in this high-risk group, thus guiding appropriate post-emergency care.

Interpretation: One patient out of every 10 presented with delayed hemothorax after discharge from the emergency department. Implementation of this validated clinical decision rule for minor thoracic injury could guide emergency discharge plans.

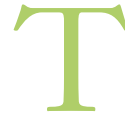

horacic injuries represent about $5 \%$ to $15 \%$ of all injuries treated in the acute care setting. ${ }^{1,2}$ In 2005, the US National Hospital Ambulatory Medical Care Survey reported more than 800000 visits to the emergency department each year for chest injuries. ${ }^{1}$ Most blunt thoracic injuries are considered minor, and two-thirds of patients with rib fractures are treated as outpatients. ${ }^{1,3}$ Minor thoracic injuries cause substantial morbidity ${ }^{4-7}$ and pain, ${ }^{8}$ but rarely death. ${ }^{9}$

Physicians have focused on delayed pneumonia as a complication of minor thoracic injury or rib fracture. ${ }^{10,11}$ However, delayed pneumonia is rare, with reported incidence less than $2 \%$ among patients with minor thoracic injury. ${ }^{12,13}$ Delayed hemothorax, another complication, seems to be more frequent than delayed pneumonia. ${ }^{14-17}$ A 2004 prospective study in Europe found that $7.4 \%$ of 709 outpatients who presented to the emergency department with at least 1 rib fracture received a diagnosis of hemothorax within 14 days. ${ }^{18}$ More recently, our group reported an incidence of $11.8 \%$ for delayed hemothorax in a prospective Canadian cohort study. ${ }^{19}$ We showed that hemothorax was associated with functional decline at 90 days after the injury and precluded regular activ-

\section{Competing interests: None declared.}

This article has been peer reviewed.

Correspondence to: Marcel Émond, marcelemond1 @ me.com CMAJ Open 2017. DOI:10.9778/cmajo.20160096 
ities for a substantial number of days. ${ }^{20}$ Our team also showed substantial discrepancies in follow-up practices for patients with minor thoracic injury after discharge from the emergency department. ${ }^{21}$ Misthos and colleagues ${ }^{18}$ suggested a general 2-week follow-up protocol for all patients with minor thoracic injury, which would place high demands on the limited follow-up resources in Canadian health care centres. No large study has yet assessed predictors of delayed hemothorax to guide management after medical evaluation in the emergency department, taking into account limited care resources. Our primary objective for the study reported here was to derive and validate a clinical decision rule for delayed hemothorax in patients with minor thoracic injury discharged from the emergency department.

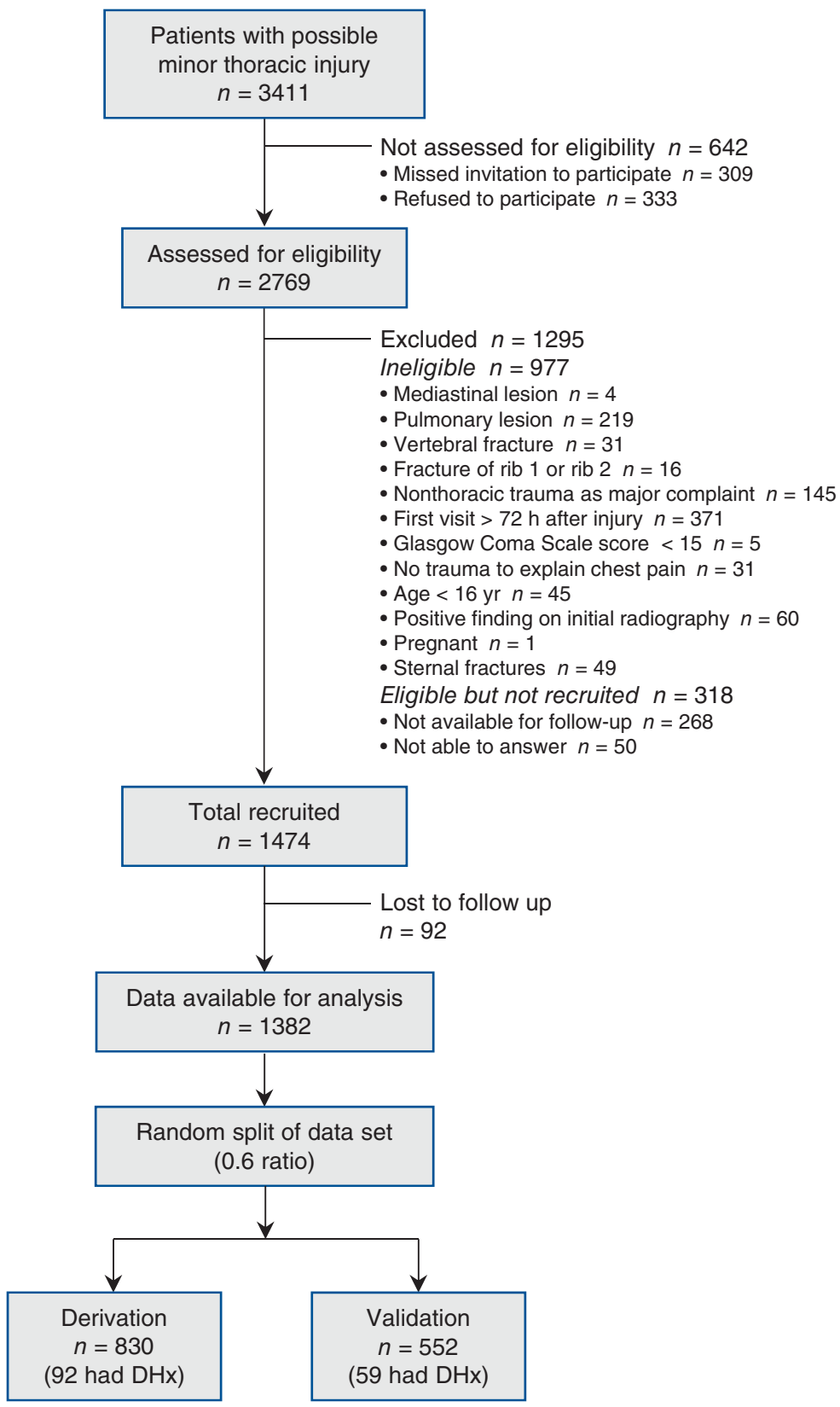

Figure 1: Flow diagram for patients in a study to derive and validate a clinical decision rule for delayed hemothorax $(\mathrm{DHx})$ after minor thoracic injury. Patients included in the study were recruited in Quebec emergency departments between November 2006 and May 2012. 


\section{OPEN}

\section{Methods}

\section{Setting}

We conducted this prospective observational cohort study from November 2006 to May 2012 in 4 Canadian universityaffiliated emergency departments: 2 level-1 trauma centres (Hôpital de l'Enfant-Jésus, Quebec City; Hôpital du SacréCoeur de Montréal, Montréal), a level-2 trauma centre (Centre hospitalier de Charles-Lemoyne, Greenfield Park, Que.) and a nontrauma centre (Centre hospitalier de l'Université Laval, Quebec City).

\section{Study design}

We included patients 16 years of age or older with a main medical complaint of minor thoracic injury. Minor thoracic injury was defined by the presence of any of the following: chest abrasion, chest contusion or "traumatic" chest pain, or suspected or confirmed rib fracture on radiography. This broad, pragmatic definition represents all potential types of minor chest trauma seen in the emergency department and was used to allow general reproducibility of results.

All participants were discharged from the emergency department after receiving care from the attending physician. The exclusion criteria were confirmed diagnosis of hemothorax, pneumothorax, lung contusion, flail chest or any other important thoracic or abdominal internal injury at the initial visit; inability to attend follow-up appointments; and presentation to the emergency department more than 3 days after the injury. This cut-off was based on a previous publication which showed that $90 \%$ of patients seek medical attention within 72 hours. $^{21}$

The attending physician performed initial care, medical evaluation and standardized data collection and ordered mandatory chest and rib radiography. Patients received usual management, including treatment for pain and discharge instructions. They returned for standardized medical outpatient evaluations at 7 and 14 days after discharge. These visits included pain assessment, clinical examination and mandatory upright chest radiography, to assess for possible delayed complications. A standardized data collection sheet was used for each medical evaluation. Candidate variables for the clinical decision rule were established, following a literature review, by consensus among the authors. Research nurses performed the 30- and 90-day evaluations through telephone interviews, aiming to uncover previously missed complications. Patients lost to follow-up were those with no outpatient visit at 7 or 14 days. Interobserver agreement between emergency physicians and research nurses was assessed on clinical variables for about $10 \%$ of the derivation cohort. The study complied with the STROBE statement on observational epidemiologic studies. ${ }^{22}$

\section{Outcomes}

Delayed hemothorax, the primary complication in this study, was considered to be present if any pleural fluid was noted on follow-up upright chest radiographs (as stated in the radiologist's report) at 7 or 14 days after discharge. No

\section{Table 1: Characteristics of study participants and patients} lost to follow-up

\begin{tabular}{|c|c|c|}
\hline \multirow[b]{2}{*}{ Characteristic } & \multicolumn{2}{|c|}{ Group; no. (\%) of patients* } \\
\hline & $\begin{array}{l}\text { Participants } \\
n=1382\end{array}$ & $\begin{array}{l}\text { Lost to follow-up } \\
\qquad n=92\end{array}$ \\
\hline \multicolumn{3}{|l|}{ Demographic } \\
\hline Age, yr, mean \pm SD & $52.5 \pm 16.7$ & $44.8 \pm 17.9$ \\
\hline No. aged $\geq 65 \mathrm{yr}$ & $341(24.7)$ & $13(14.1)$ \\
\hline Sex, male & $868(62.8)$ & $60(65.2)$ \\
\hline \multicolumn{3}{|l|}{ Mechanism of injury† } \\
\hline Simple fall & $482(35.0)$ & $36(39.1)$ \\
\hline Fall above ground level & $314(22.8)$ & $14(15.2)$ \\
\hline Motor vehicle crash & $339(24.6)$ & $16(17.4)$ \\
\hline Pedestrian v. car & $14(1.0)$ & $1(1.1)$ \\
\hline Cyclist v. car & $10(0.7)$ & $1(1.1)$ \\
\hline Direct hit & $142(10.3)$ & $20(21.7)$ \\
\hline Other & $78(5.7)$ & $4(4.3)$ \\
\hline$\geq 1$ pre-existing comorbidity & $333(24.1)$ & $16(17.4)$ \\
\hline \multicolumn{3}{|l|}{ Smoking status $\ddagger$} \\
\hline Former smoker & $297(25.3)$ & $4(9.8)$ \\
\hline Current smoker & $353(30.1)$ & $25(61.0)$ \\
\hline Never smoker & $522(44.5)$ & $12(29.3)$ \\
\hline Alcohol intoxication & $92(6.7)$ & $4(4.3)$ \\
\hline \multicolumn{3}{|l|}{$\begin{array}{l}\text { Pre-injury antiplatelet/ } \\
\text { anticoagulant medication }\end{array}$} \\
\hline ASA & $229(16.6)$ & $7(7.6)$ \\
\hline Clopidogrel & $21(1.5)$ & $1(1.1)$ \\
\hline Warfarin & $51(3.7)$ & $5(5.4)$ \\
\hline Any & $278(20.1)$ & $12(13.0)$ \\
\hline \multicolumn{3}{|l|}{$\begin{array}{l}\text { Triage vital signs, mean } \pm \text { SD } \\
\text { or median }(I Q R)\end{array}$} \\
\hline Heart rate, beats/min & $80.8 \pm 14.1$ & $81.3 \pm 14.0$ \\
\hline Oxygen saturation, $\%$ & $97.7 \pm 1.9$ & $97.6 \pm 2.1$ \\
\hline $\begin{array}{l}\text { Systolic blood pressure, } \\
\mathrm{mm} \mathrm{Hg}\end{array}$ & $140.5 \pm 20.7$ & $136.6 \pm 19.1$ \\
\hline Respiratory rate, breaths/min & $16(16-20)$ & $16(16-20)$ \\
\hline \multicolumn{3}{|l|}{ No. of rib fractures§ף } \\
\hline None & $914(67.0)$ & $75(81.5)$ \\
\hline 1 & $203(14.9)$ & $10(10.9)$ \\
\hline 2 & $130(9.5)$ & $4(4.3)$ \\
\hline$\geq 3$ & $117(8.6)$ & $3(3.3)$ \\
\hline Atelectasis & $129(9.3)$ & $2(2.2)$ \\
\hline \multicolumn{3}{|c|}{$\begin{array}{l}\text { Note: } A S A=\text { acetylsalicylic acid, IQR = interquartile range, } S D=\text { standard } \\
\text { deviation. } \\
\text { "Except where indicated otherwise. } \\
\text { tFor mechanism of injury, data were available for } 1379 \text { of the participants. } \\
\text { †For smoking status, data were available for } 1172 \text { of the participants and } 41 \text { of } \\
\text { those lost to follow-up. } \\
\text { §For number of rib fractures, data were available for } 1364 \text { of the participants. } \\
\text { ๆConfirmed by initial radiography. }\end{array}$} \\
\hline
\end{tabular}


robust guidelines are available on the amount of pleural fluid that is considered clinically relevant; therefore, any pleural fluid was considered a positive finding, because this should be investigated, especially in older patients. ${ }^{23}$ Radiologists were blinded to data collection for this study. Interobserver agreement between emergency physicians and radiologists was assessed in the derivation cohort. Potentially important delayed hemothorax was considered to have been missed if reported by patients for the first time at the 30- or 90-day telephone follow-up.

\section{Statistical analysis}

The analysis involved distinct derivation and validation data sets. We derived models with one set of patients, and the best of these models (according to the $\mathrm{C}$ statistic) was subsequently validated with a different set of patients. We described clinical and demographic characteristics using univariable analyses.
Given the possibly high morbidity ${ }^{2,14,20}$ associated with minor thoracic injury and limited post-emergency resources, our objective was to derive and validate a stratification model with at least $90 \%$ sensitivity for delayed hemothorax, the highest possible specificity (near 50\%) and the most parsimonious model achievable. We used log-binomial regression to identify the predictors of outcome measures. This type of analysis was preferred over logistic regression because it provides accurate relative risks (RRs), rather than odds ratios, when the incidence of an outcome is higher than $10 \% .{ }^{24}$ The cut point for continuous variables was assessed by iteration. We used the forward stepwise method to derive the model. The variables found to be both reliable ( $\kappa$ coefficient $>0.5$ ) and strongly associated with the outcome measures according to univariable analysis $(p<0.15)$ were considered for multivariable analysis. We reported predictive capacities of the model for both the derivation

\begin{tabular}{|c|c|c|c|}
\hline \multirow[b]{2}{*}{ Characteristic } & \multicolumn{2}{|c|}{ Cohort; no. (\%) of patients* } & \multirow[b]{2}{*}{$p$ value $\dagger$} \\
\hline & $\begin{array}{c}\text { Derivation } \\
n=830\end{array}$ & $\begin{array}{l}\text { Validation } \\
n=552\end{array}$ & \\
\hline \multicolumn{4}{|l|}{ Demographic } \\
\hline Age, yr, mean $\pm S D$ & $53.3 \pm 16.2$ & $51.3 \pm 17.4$ & 0.03 \\
\hline No. aged $\geq 65 \mathrm{yr}$ & $210(25.3)$ & $131(23.7)$ & 0.5 \\
\hline Sex, male & $522(62.9)$ & $346(62.7)$ & 0.9 \\
\hline \multicolumn{4}{|l|}{ Clinical } \\
\hline Pleuritic chest pain & $437(52.6)$ & $295(53.4)$ & 0.2 \\
\hline Dyspnea at rest & $55(6.6)$ & $36(6.5)$ & 0.9 \\
\hline Dyspnea & $177(21.3)$ & $121(21.9)$ & 0.8 \\
\hline Hemoptysis & $6(0.7)$ & $5(0.9)$ & $0.8^{* *}$ \\
\hline \multicolumn{4}{|l|}{ Mechanism of injury } \\
\hline Simple fall & $294(35.9)$ & $188(34.5)$ & 0.6 \\
\hline Fall above ground level & $184(22.5)$ & $129(23.7)$ & 0.6 \\
\hline Motor vehicle crash & $200(24.4)$ & $139(25.5)$ & 0.6 \\
\hline Cyclist v. car & $5(0.6)$ & $5(0.9)$ & 0.5 \\
\hline Direct hit & $85(10.4)$ & $57(10.4)$ & $>0.9$ \\
\hline Other & $51(6.2)$ & $27(5.0)$ & 0.3 \\
\hline \multicolumn{4}{|l|}{ Pre-existing comorbidity } \\
\hline COPD & $34(4.1)$ & $11(2.0)$ & 0.03 \\
\hline Asthma & $77(9.3)$ & $35(6.3)$ & 0.05 \\
\hline Osteoporosis & $60(7.2)$ & $40(7.2)$ & $>0.9$ \\
\hline Diabetes mellitus & $85(10.2)$ & $48(8.7)$ & 0.3 \\
\hline$\geq 1$ pre-existing comorbidity & $213(25.7)$ & $119(21.6)$ & 0.09 \\
\hline \multicolumn{4}{|l|}{ Smoking status§ } \\
\hline Former smoker & $179(25.0)$ & $117(25.7)$ & 0.9 \\
\hline Current smoker & $219(30.6)$ & $134(29.5)$ & 0.6 \\
\hline Never smoker & $318(44.4)$ & $204(44.8)$ & 0.9 \\
\hline Alcohol intoxication & $56(6.7)$ & $36(6.5)$ & 0.9 \\
\hline
\end{tabular}


Table 2 (part 2 of 2): Characteristics of the derivation and validation cohorts

\begin{tabular}{|c|c|c|c|}
\hline \multirow[b]{2}{*}{ Characteristic } & \multicolumn{2}{|c|}{ Cohort; no. $(\%)$ of patients* } & \multirow[b]{2}{*}{$p$ value } \\
\hline & $\begin{array}{l}\text { Derivation } \\
n=830\end{array}$ & $\begin{array}{l}\text { Validation } \\
n=552\end{array}$ & \\
\hline \multicolumn{4}{|c|}{ Pre-injury antiplatelet/anticoagulant medication } \\
\hline ASA & $138(16.6)$ & $90(16.3)$ & 0.9 \\
\hline Clopidogrel & $14(1.7)$ & $7(1.3)$ & 0.5 \\
\hline Warfarin & $32(3.9)$ & $19(3.4)$ & 0.7 \\
\hline Any & $171(20.6)$ & $106(19.2)$ & 0.5 \\
\hline \multicolumn{4}{|l|}{$\begin{array}{l}\text { Results of physical examination in } \\
\text { emergency department }\end{array}$} \\
\hline Chest abrasion & $36(4.3)$ & $29(5.3)$ & 0.4 \\
\hline Chest contusion & $154(18.6)$ & $95(17.2)$ & 0.5 \\
\hline Bone crepitus & $24(2.9)$ & $13(2.4)$ & 0.5 \\
\hline Other & $213(25.7)$ & $139(25.2)$ & 0.8 \\
\hline \multicolumn{4}{|l|}{ Vital signs, mean \pm SD } \\
\hline Heart rate, beats/min & $81.0 \pm 14.1$ & $80.6 \pm 14.1$ & 0.7 \\
\hline Oxygen saturation, \% & $97.6 \pm 1.9$ & $97.9 \pm 1.9$ & 0.01 \\
\hline Systolic blood pressure, $\mathrm{mm} \mathrm{Hg}$ & $141.0 \pm 21.4$ & $139.6 \pm 19.6$ & 0.2 \\
\hline Diastolic blood pressure, $\mathrm{mm} \mathrm{Hg}$ & $82.1 \pm 12.4$ & $81.1 \pm 12.5$ & 0.1 \\
\hline Respiratory rate, breaths/min & $17.7 \pm 3.1$ & $17.8 \pm 3.5$ & $0.9 \dagger †$ \\
\hline \multicolumn{4}{|l|}{ No. of rib fracturesף } \\
\hline None & $560(68.5)$ & $354(64.8)$ & 0.2 \\
\hline 1 & $112(13.7)$ & $91(16.7)$ & 0.1 \\
\hline 2 & $78(9.5)$ & $52(9.5)$ & $>0.9$ \\
\hline$\geq 3$ & $68(8.3)$ & $49(9.0)$ & 0.6 \\
\hline \multicolumn{4}{|l|}{ Location of fractureq } \\
\hline Any high rib (3-5) & $59(7.2)$ & $47(8.6)$ & 0.3 \\
\hline Any mid rib (6-9) & $194(23.7)$ & $132(24.2)$ & 0.8 \\
\hline Any high or mid rib (3-9) & $221(27.0)$ & $159(29.1)$ & 0.4 \\
\hline Any low rib (10-12) & $81(9.9)$ & $54(9.9)$ & $>0.9$ \\
\hline Atelectasis $†$ & $84(10.1)$ & $45(8.2)$ & 0.2 \\
\hline \multicolumn{4}{|c|}{$\begin{array}{l}\text { Note: } A S A=\text { acetylsalicylic acid, } C O P D=\text { chronic obstructive pulmonary disease, } S D=\text { standard deviation. } \\
\text { *Except where indicated otherwise. } \\
\text { †All statistical analyses were performed with the Student } t \text { test or } \chi^{2} \text { test, except where indicated otherwise. } \\
\text { fFor mechanism of injury, data were available for } 819 \text { patients in the derivation group and } 545 \text { in the validation group. There were no } \\
\text { patients with pedestrian v. car as the mechanism of injury. } \\
\text { \$For smoking status, data were available for } 716 \text { patients in the derivation group and } 455 \text { patients in the validation group. } \\
\text { ๆNumber and location of fractures were confirmed by initial radiography. For these variables, data were available for } 818 \text { patients in the } \\
\text { derivation group and } 546 \text { in the validation group. } \\
{ }^{* *} \text { Fisher exact test. } \\
\text { ††Wilcoxon test. }\end{array}$} \\
\hline
\end{tabular}

and the validation phases. The multivariable stratification model allows clinicians to choose their own cut point, favouring either sensitivity or specificity. ${ }^{25}$ This approach could be helpful in clinical practice settings, because it has been shown that the use of clinical decision rules differs between US and Canadian physicians. ${ }^{26}$

We aimed to enter about 10 to 15 outcomes per variable in the log-binomial model. ${ }^{27}$ According to previous reports of the incidence of delayed hemothorax $(7 \%$ to
$12 \%^{18,28}$ ), we determined that a cohort of 800 patients for the derivation phase would allow 6 candidate variables for creation of the clinical decision rule, and a cohort of 500 patients for the validation phase would allow refinement and validation of a rule with at least 4 variables. ${ }^{27}$ Thus, a total cohort of 1300 patients was needed. Participants were randomly assigned to the derivation or validation set during analyses based on previous optimal suggested scenarios. $^{29,30}$ 


\section{Ethics approval}

This study was approved by the research ethics board of each institution, and all participants provided written consent.

\section{Results}

During the study period, 2769 patients were screened for eligibility, and 1474 were recruited, with 92 of these being lost to follow-up (Figure 1). Relative to patients included in the study, those lost to follow-up were younger (mean age \pm standard deviation $44.8 \pm 17.9$ yr v. $52.5 \pm 16.7 \mathrm{yr}, p=0.001)$, more of them were smokers $(61.0 \%$ [25/41] v. $30.1 \%$ [353/1172], $p<0.001)$, fewer had rib fractures $(81.5 \%$ [75/92] v. $67.0 \%$ [914/1364] with no fractures, $p=0.04$ ) and fewer had regular use of acetylsalicylic acid (7.6\% [7/92] v. $16.6 \%$ [229/1382], $p=0.02)$. No other significant clinical differences were observed (Table 1). Data for 1382 patients were available for the analyses. The 7-, 14-, 30- and 90-day follow-up evaluations were completed for 1261 (91.2\%), $1133(82.0 \%)$, $1036(75.0 \%)$ and $826(59.8 \%)$ patients, respectively. Overall, 1341 patients $(97.0 \%)$ had at least 1 medical or research evaluation within the first 14 days after discharge.

\begin{tabular}{|c|c|c|c|c|}
\hline \multirow[b]{2}{*}{ Characteristic } & \multicolumn{3}{|c|}{ Group; no. (\%) of patients* } & \multirow[b]{2}{*}{$p$ value $\dagger$} \\
\hline & $\begin{array}{l}\text { Derivation } \\
n=92\end{array}$ & $\begin{array}{l}\text { Validation } \\
\quad n=59\end{array}$ & $\begin{array}{c}\text { Total } \\
n=151\end{array}$ & \\
\hline \multicolumn{5}{|l|}{ Demographic } \\
\hline Age, yr, mean \pm SD & $59.6 \pm 13.2$ & $58.1 \pm 15.6$ & $59.0 \pm 14.2$ & 0.5 \\
\hline No. aged $\geq 65 \mathrm{yr}$ & $27(29.3)$ & $19(32.2)$ & $46(30.5)$ & 0.7 \\
\hline Sex, male & $64(69.6)$ & $41(69.5)$ & $105(69.5)$ & $>0.9$ \\
\hline \multicolumn{5}{|l|}{ Clinical } \\
\hline Pleuritic chest pain & $48(52.2)$ & $28(47.5)$ & $76(50.3)$ & 0.6 \\
\hline Severe chest pain $\ddagger$ & $46(63.9)$ & $30(65.2)$ & $76(64.4)$ & 0.9 \\
\hline Dyspnea at rest & $10(10.9)$ & $4(6.8)$ & $14(9.3)$ & 0.4 \\
\hline Dyspnea & $21(22.8)$ & $12(20.3)$ & $33(21.9)$ & 0.8 \\
\hline Hemoptysis & $0(0.0)$ & $1(1.7)$ & $1(0.7)$ & $0.4 \dagger \dagger$ \\
\hline \multicolumn{5}{|l|}{ Mechanism of injury§ } \\
\hline Simple fall & $27(29.7)$ & $28(48.3)$ & $55(36.9)$ & 0.02 \\
\hline Fall above ground level & $33(36.3)$ & $16(27.6)$ & $49(32.9)$ & $>0.9$ \\
\hline Motor vehicle crash & $21(23.1)$ & $12(20.7)$ & $33(22.1)$ & 0.7 \\
\hline Other & $10(11.0)$ & $2(3.4)$ & $12(8.1)$ & 0.4 \\
\hline \multicolumn{5}{|l|}{ Pre-existing comorbidity } \\
\hline COPD & $3(3.3)$ & $2(3.4)$ & $5(3.1)$ & $>0.9 \dagger \dagger$ \\
\hline Asthma & $4(4.3)$ & $3(5.1)$ & $7(4.6)$ & $>0.9 \dagger \dagger$ \\
\hline Osteoporosis & $4(4.3)$ & $6(10.2)$ & $10(6.6)$ & $0.2 \dagger \dagger$ \\
\hline Diabetes mellitus & $10(10.9)$ & $7(11.9)$ & $17(11.3)$ & 0.9 \\
\hline$\geq 1$ pre-existing comorbity & $19(20.7)$ & $16(27.1)$ & $35(23.2)$ & 0.4 \\
\hline \multicolumn{5}{|l|}{ Smoking status } \\
\hline Former smoker & $15(19.5)$ & $17(34.0)$ & $32(25.2)$ & 0.04 \\
\hline Current smoker & $30(39.0)$ & $15(30.0)$ & $45(35.4)$ & 0.3 \\
\hline Never smoker & $32(41.6)$ & $18(36.0)$ & $50(39.4)$ & 0.5 \\
\hline Alcohol intoxication & $9(9.8)$ & $5(8.5)$ & $14(9.3)$ & 0.8 \\
\hline \multicolumn{5}{|l|}{$\begin{array}{l}\text { Pre-injury antiplatelet/ } \\
\text { anticoagulant medication }\end{array}$} \\
\hline ASA & $18(19.6)$ & $11(18.6)$ & $29(19.2)$ & 0.9 \\
\hline Clopidogrel & $0(0.0)$ & $0(0.0)$ & $0(0.0)$ & NA \\
\hline Warfarin & $3(3.3)$ & $3(5.1)$ & $6(4.0)$ & $0.7 \dagger \dagger$ \\
\hline Any & $20(21.7)$ & $13(22.0)$ & $33(21.9)$ & $>0.9$ \\
\hline
\end{tabular}




\begin{tabular}{|c|c|c|c|c|}
\hline \multirow[b]{2}{*}{ Characteristic } & \multicolumn{3}{|c|}{ Group; no. (\%) of patients* } & \multirow[b]{2}{*}{$p$ value } \\
\hline & $\begin{array}{l}\text { Derivation } \\
n=92\end{array}$ & $\begin{array}{l}\text { Validation } \\
n=59\end{array}$ & $\begin{array}{c}\text { Total } \\
n=151\end{array}$ & \\
\hline \multicolumn{5}{|l|}{$\begin{array}{l}\text { Results of physical examination } \\
\text { in emergency department }\end{array}$} \\
\hline Chest abrasion & $3(3.3)$ & $2(3.4)$ & $5(3.3)$ & $>0.9 \dagger \dagger$ \\
\hline Chest contusion & $12(13.0)$ & $5(8.5)$ & $17(11.3)$ & 0.4 \\
\hline Clinical rib fracture & $36(39.1)$ & $31(52.5)$ & $67(44.4)$ & 0.1 \\
\hline Bone crepitus & $3(3.3)$ & $1(1.7)$ & $4(2.6)$ & $>0.9 \dagger \dagger$ \\
\hline Other & $17(18.5)$ & $17(28.8)$ & $34(22.5)$ & 0.1 \\
\hline \multicolumn{5}{|l|}{ Vital signs, mean $\pm S D$} \\
\hline Heart rate, beats/min & $80.3 \pm 12.8$ & $79.3 \pm 15.7$ & $79.9 \pm 14.0$ & 0.7 \\
\hline Oxygen saturation, \% & $97.2 \pm 2.1$ & $97.2 \pm 1.9$ & $97.2 \pm 2.0$ & 0.9 \\
\hline Respiratory rate, breaths/min & $18.3 \pm 3.3$ & $17.6 \pm 3.3$ & $18.0 \pm 3.3$ & $0.3 \neq \ddagger$ \\
\hline \multicolumn{5}{|l|}{ No. of rib fractures ${ }^{\star *}$} \\
\hline None & $30(32.6)$ & $19(32.2)$ & $49(32.5)$ & $>0.9$ \\
\hline 1 & $21(22.8)$ & $10(16.9)$ & $31(20.5)$ & 0.4 \\
\hline 2 & $13(14.1)$ & $13(22.0)$ & $26(17.2)$ & 0.2 \\
\hline$\geq 3$ & $28(30.4)$ & $17(28.8)$ & $45(29.8)$ & 0.8 \\
\hline \multicolumn{5}{|l|}{ Location of fracture ${ }^{\star *}$} \\
\hline Any high rib (3-5) & $22(23.9)$ & $14(23.7)$ & $36(23.8)$ & $>0.9$ \\
\hline Any mid rib (6-9) & $52(56.5)$ & $32(54.2)$ & $84(55.6)$ & 0.8 \\
\hline Any high or mid rib (3-9) & $60(65.2)$ & $38(64.4)$ & $98(64.9)$ & 0.9 \\
\hline Any low rib (10-12) & $14(15.2)$ & $9(15.3)$ & $23(15.2)$ & $>0.9$ \\
\hline Atelectasis† & $18(19.6)$ & $10(16.9)$ & $28(18.5)$ & 0.7 \\
\hline \multicolumn{5}{|c|}{ 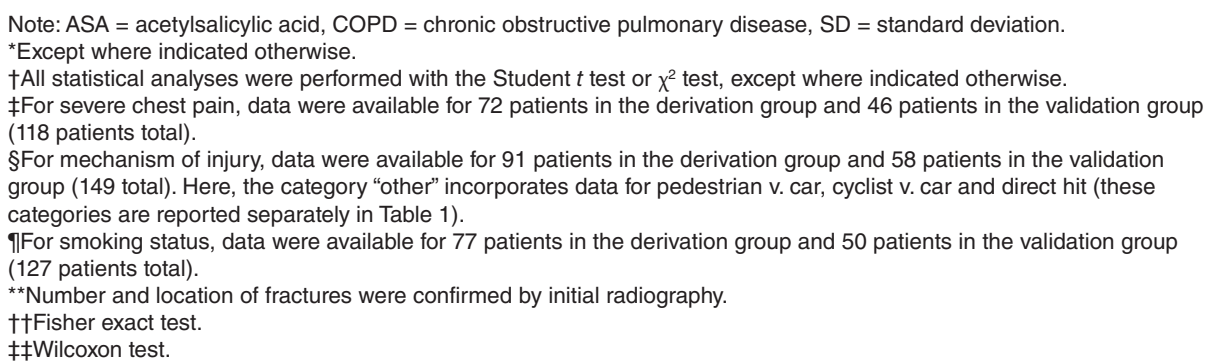 } \\
\hline
\end{tabular}

In the study cohort, 868 participants $(62.8 \%)$ were men, and the mean age was 52.5 years (Table 1 ). Hemothorax was identified at the 7-day follow-up for 1180 (85.4\%) of the patients. Delayed hemothorax occurred within the 14-day follow-up period for 151 patients (10.9\%): 92 (11.1\%) in the derivation phase and $59(10.7 \%)$ in the validation phase. No cases of hemothorax were reported after the 14-day evaluations. Only 5 patients underwent drainage of the hemothorax, and no deaths were reported during the study period. Table 2 shows the clinical and demographic characteristics of study participants in the derivation and validation groups. Patients in the derivation group were slightly older $(53.3$ v. $51.3 \mathrm{yr})$, and had higher rates of chronic obstructive pulmonary disease (4.1\% [34/830] v. $2.0 \%$ [11/552]) and asthma (9.3\% [77/830] v. $6.3 \%[35 / 552])$. No other significant clinical differences were observed. Characteristics of participants with delayed hemothorax in both phases are described in Table 3.

\section{Clinical decision rule for minor thoracic injury}

All candidate variables had moderate to high interobserver agreement ( $\kappa$ coefficient $>0.5$; Table 4$)$. Table 5 shows the derived and validated log-binomial model and RRs with $95 \%$ confidence intervals (CIs). The final model included 4 variables: age $\geq 70$ years old (RR 3.84, 95\% CI 1.71-8.60), fracture in the high to mid rib region (ribs 3-9; RR 3.37, 95\% CI 2.14-5.31), age 45 to 70 years (RR 2.72 , 95\% CI 1.26-5.89) and presence of 3 or more rib fractures (RR 1.97, 95\% CI 1.31-2.95). The use of anticoagulants was initially included on 
a theoretical basis, but this variable was highly correlated with patient age and was therefore omitted from the final model.

The final derived and validated clinical decision rule had a maximum score of 5 . Sensitivity and specificity values for the model for both cohorts are presented in Table 6 . The moderate-risk (score 2 or 3 ) and high-risk (score 4 or 5 ) levels had equivalent sensitivities and specificities across cohorts. The area under the receiver operating characteristic curve was 0.78 (95\% CI 0.74-0.82) for the derivation cohort and 0.74 (95\% CI $0.67-$ 0.81 ) for the validation cohort. In the high-risk category, about 1 in every 3 patients experienced delayed hemothorax.

Table 4: Interobserver agreement for potential predictors

\begin{tabular}{|lc|}
\hline Predictor & Kappa $(95 \% \mathrm{Cl})$ \\
\hline Clinical history $(\boldsymbol{n}=\mathbf{6 2})^{\star}$ & \\
\hline Mechanism of injury & $0.97(0.91-1.00)$ \\
\hline Presence of comorbity & $0.79(0.51-1.00)$ \\
\hline COPD & $0.73(0.48-0.98)$ \\
\hline Asthma & $0.58(0.21-0.95)$ \\
\hline Osteoporosis & $1.00(1.00-1.00)$ \\
\hline Diabetes mellitus &
\end{tabular}

Pre-injury antiplatelet/

anticoagulant medication

\begin{tabular}{|c|c|}
\hline ASA & $0.91(0.82-1.00)$ \\
\hline Warfarin & $1.00(1.00-1.00)$ \\
\hline Clopidogrel & $1.00(1.00-1.00)$ \\
\hline Any & $0.92(0.84-1.00)$ \\
\hline \multicolumn{2}{|l|}{ Clinical } \\
\hline Severe chest pain & $0.54(0.37-0.71)$ \\
\hline Pleuretic chest pain & $0.41(0.26-0.56)$ \\
\hline Smoking status & $0.87(0.78-0.96)$ \\
\hline Alcohol intoxication & $0.87(0.72-1.00)$ \\
\hline \multicolumn{2}{|l|}{ Radiologic findings $(n=299) \dagger$} \\
\hline \multicolumn{2}{|l|}{ No. of confirmed rib fractures } \\
\hline$\geq 1$ & $0.60(0.56-0.65)$ \\
\hline$\geq 3$ & $0.47(0.38-0.56)$ \\
\hline \multicolumn{2}{|l|}{ Location of fractures } \\
\hline Any high rib (3-5) & $0.59(0.46-0.73)$ \\
\hline At least 2 high ribs (3-5) & $0.59(0.39-0.79)$ \\
\hline Any mid rib (6-9) & $0.50(0.42-0.59)$ \\
\hline At least 2 mid ribs (6-9) & $0.37(0.23-0.50)$ \\
\hline Any low rib (10-12) & $0.56(0.44-0.67)$ \\
\hline At least 2 low ribs (10-12) & $0.39(0.14-0.63)$ \\
\hline Atelectasis & $0.58(0.50-0.66)$ \\
\hline \multicolumn{2}{|c|}{$\begin{array}{l}\text { Note: } \mathrm{ASA}=\text { acetylsalicylic acid, } \mathrm{Cl}=\text { confidence interval, } \mathrm{COPD}=\text { chronic } \\
\text { obstructive pulmonary disease. } \\
\text { *For a total of } 62 \text { patients, an emergency physician and nurse performed an } \\
\text { assessment of the clinical history. } \\
\text { †For a total of } 299 \text { patients, a radiologist and an emergency physician performed } \\
\text { radiologic evaluation of the number and location of rib fractures. }\end{array}$} \\
\hline
\end{tabular}

\section{Interpretation}

In this study, we developed a clinical decision rule for minor thoracic injury, which takes into account 4 clinically sensitive and robust variables to predict hemothorax in the 14 days after discharge from the emergency department. Use of this clinical decision rule in moderate- and high-risk groups will permit efficient use of follow-up services. Almost one-third of patients at high risk will have a hemothorax on follow-up, and the clinical decision rule has specificity of more than $90 \%$ for that category of patients. Use of this rule, in conjunction with risk stratification, may therefore promote efficient use of limited resources and meets our targeted sensitivity and specificity.

Until recently, only a few studies have reported potential predictive factors for delayed complications after minor thoracic injury, but none were derived and validated according to the methodologic standards for development of clinical decision rules..$^{27,31,32}$ Most studies have reported that patients with at least 1 rib fracture represented about $90 \%$ of cases of delayed hemothorax; $;^{14,18,33,34}$ however, delayed hemothorax also has been reported in the absence of rib fractures. ${ }^{16,18}$ One retrospective study reported a prodrome of pain and acute dyspnea in $82 \%$ of emergency patients with delayed hemothorax after discharge ${ }^{17}$ whereas other prospective prediction studies reported that the presence of thoracic contusions alone could represent a predictive factor for delayed complications. ${ }^{3,18}$ Age over 45 years $^{35}$ or age over 65 years $^{36}$ was also considered as a possible stand-alone predictive factor. The incidence of delayed hemothorax in the current study was slightly higher than in previous studies, which could be attributed to our prospective design, the important follow-up rate and the slightly older age of our cohort relative to previous studies. ${ }^{18,34}$ In their prospective study, Misthos and colleagues ${ }^{18}$ reported a $7.4 \%$ incidence of delayed hemothorax in an outpatient setting among patients under 65 years of age who underwent cardiothoracic evaluation in the emergency department. However, some patients with minor thoracic injury who were discharged without any cardiothoracic consultation may have had undetected hemothorax, which would have introduced selection bias. Patients 65 years of age or older accounted for $24.7 \%$ of our study cohort versus $21.5 \%$ in the study by Sharma and colleagues. ${ }^{34}$ Moreover, the identification of older patients with delayed hemothorax is of importance, because it has been suggested that surgical drainage could be an early treatment option in these patients. ${ }^{23}$

Physicians' practice is highly heterogeneous in the management of minor thoracic injury, with or without rib fractures, especially in terms of discharge follow-up plans and admission. ${ }^{21}$ Because hemothorax is associated with important consequences, such as acute respiratory distress syndrome, emphysema, functional limitations, infections and longer lengths of stay in hospital,,$^{20,37-41}$ post-emergency planning creates challenges for both health care professionals and patients. It is impossible to follow all patients with minor thoracic injury in overcrowded emergency departments. In Canada, the current wait time for a follow-up appointment with a family physician is about 30 days. ${ }^{42}$ Current post-emergency resources would be insufficient to meet the demand if all 


\section{OPEN}

\begin{tabular}{|c|c|c|c|c|}
\hline Characteristic & $\mathrm{RR}(95 \% \mathrm{Cl})$ & B coefficient & $\begin{array}{l}\text { B coefficient } \\
\text { after inflation* }\end{array}$ & Points \\
\hline Age $\geq 70 \mathrm{yr}$ & $3.84(1.71-8.60)$ & 1.3447 & 2.0 & 2 \\
\hline High or mid rib fracture $†$ & $3.37(2.14-5.31)$ & 1.2156 & 1.8 & 2 \\
\hline Age $45-70 \mathrm{yr}$ & $2.72(1.26-5.89)$ & 1.0004 & 1.4 & 1 \\
\hline At least 3 rib fractures & $1.97(1.31-2.95)$ & 0.6771 & 1.0 & 1 \\
\hline Maximum total & & & & 5 \\
\hline
\end{tabular}

\begin{tabular}{|c|c|c|c|c|c|}
\hline Risk level & Score & $n$ & $\begin{array}{l}\text { Risk per } \\
\text { stratum }\end{array}$ & $\begin{array}{l}\text { Sensitivity } \\
(95 \% \mathrm{Cl})\end{array}$ & $\begin{array}{c}\text { Specificity } \\
(95 \% \mathrm{Cl})\end{array}$ \\
\hline \multicolumn{6}{|c|}{ Derivation cohort } \\
\hline \multirow[t]{2}{*}{ Low } & 0 & 199 & 0 & 100.0 & 0.0 \\
\hline & 1 & 290 & 7.6 & $100.0(96.1-100.0)$ & $27.49(24.3-30.9)$ \\
\hline Moderate & 2 or 3 & 242 & 15.7 & $76.1(66.1-84.4)$ & $64.50(60.9-67.9)$ \\
\hline High & 4 or 5 & 85 & 37.7 & $34.8(25.2-45.4)$ & $92.68(90.5-94.5)$ \\
\hline \multicolumn{6}{|c|}{ Validation cohort } \\
\hline \multirow[t]{2}{*}{ Low } & 0 & 157 & 3.82 & 100.0 & 0.0 \\
\hline & 1 & 171 & 4.7 & 89.8 (79.2-96.2) & $31.3(27.2-35.6)$ \\
\hline Moderate & 2 or 3 & 149 & 16.7 & $76.3(63.4-86.4)$ & $65.0(60.6-69.3)$ \\
\hline High & 4 or 5 & 65 & 30.8 & $33.9(22.1-47.4)$ & $90.7(87.7-93.1)$ \\
\hline
\end{tabular}

patients with minor thoracic injury were to be followed. Our clinical decision rule provides a risk stratification process that would allow cost-effective use of existing resources by identifying patients with specific minor thoracic injuries who would benefit most from follow-up. The Quebec clinical decision rule for minor thoracic injury is likely to have widespread applicability and could be used by a wide range of front-line physicians, including emergency and primary care physicians, in urban, rural and remote areas worldwide.

\section{Limitations}

This study had some limitations. Our definition of minor thoracic injury was deliberately broad, and the decision to admit patients to hospital was left to the attending physician, to reflect a pragmatic approach. However, the inclusion of patients who had only simple chest abrasion and contusion may have increased the number of patients at very low risk of delayed hemothorax. Nevertheless, because it has been reported that patients who have "simple" chest contusion without rib fracture may experience delayed hemothorax ${ }^{18}$ these patients were retained in our analysis. Furthermore, some variables may have been overlooked in the creation of the derivation models; however, a consultant statistician found no systematic bias because of missing variables. There may have been selection bias because we excluded patients who were less sick and thus less likely to seek medical care. The number of rib fractures and their location (high or mid level) was assessed by upright chest and hemithorax radiography, to increase generalizability of the rule. These variables may have been subject to classification bias because there may be underdetection of rib fractures with simple radiography relative to ultrasonography and computed tomography. The number of rib fractures was recorded from radiologists' reports, and the fractures themselves could have been misclassified, given that radiographic diagnosis of rib fracture may be imperfect. ${ }^{43}$ Lastly, because the random assignment of participants to the derivation or validation set may have improved the performance of our model, ${ }^{29,30}$ future external validation could show different classification performance. ${ }^{27,44}$

\section{Conclusion}

This large prospective study of patients with minor thoracic injury showed a $10.9 \%$ incidence of delayed hemothorax. The 
validated Quebec minor thoracic injury clinical decision rule, using 4 variables (age $\geq 70 \mathrm{yr}$, rib fracture location, age $45-70 \mathrm{yr}$ and number of rib fractures) identified patients at high risk of delayed hemothorax with $90 \%$ specificity. The Quebec minor thoracic injury rule should be further implemented to improve detection of delayed consequences in patients discharged from the emergency department.

\section{References}

1. Nawar EW, Niska RW, Xu J. National Hospital Ambulatory Medical Care Survey: 2005 emergency department summary. Adv Data 2007;(386):1-32.

2. Ziegler DW, Agarwal NN. The morbidity and mortality of rib fractures. 7 Trauma 1994;37:975-9.

3. Liman ST, Kuzucu A, Tastepe AI, et al. Chest injury due to blunt trauma. Eur 7 Cardiothorac Surg 2003;23:374-8.

4. Barnea $\mathrm{Y}$, Kashtan $\mathrm{H}$, Skornick $\mathrm{Y}$, et al. Isolated rib fractures in elderly patients: mortality and morbidity. Can 7 Surg 2002;45:43-6.

5. Little RA, Yates DW, Atkins RE, et al. The effects of minor and moderately severe accidental chest injuries on pulmonary function in man. Arch Emerg Med 1984;1:29-38.

6. Émond M, Sirois MJ, Lavoie A, et al. Short-term functional impact following acute minor thoracic injuries (MTI) [abstract]. C7EM 2009;11:292.

7. Sirmali M, Türüt $H$, Topçu $S$, et al. A comprehensive analysis of traumatic rib fractures: morbidity, mortality and management. Eur 7 Cardiothorac Surg 2003;24:133-8.

8. Daoust R, Émond M, Bergeron E, et al. Risk factors of significant pain syndrome 90 days after minor thoracic injury: trajectory analysis. Acad Emerg Med 2013;20:1139-45.

9. Ioannidis G, Papaioannou A, Hopman WM, et al. Relation between fractures and mortality: results from the Canadian Multicentre Osteoporosis Study. CMA7 2009; 181:265-71

10. Brasel KJ, Guse CE, Layde P, et al. Rib fractures: relationship with pneumonia and mortality. Crit Care Med 2006;34:1642-6.

11. Antonelli M, Moro ML, Capelli O, et al. Risk factors for early onset pneumonia in trauma patients. Chest 1994;105:224-8.

12. Chauny JM, Emond M, Plourde $M$, et al. Patients with rib fractures do not develop delayed pneumonia: a prospective, multicenter cohort study of minor thoracic injury. Ann Emerg Med 2012;60:726-31.

13. Ho SW, Teng YH, Yang SF, et al. Risk of pneumonia in patients with isolated minor rib fractures: a nationwide cohort study. BM7 Open 2017;7:e013029.

14. Ross RM, Cordoba A. Delayed life-threatening hemothorax associated with rib fractures. 7 Trauma 1986;26:576-8.

15. Blair E, Topuzlu C, Davis JH. Delayed or missed diagnosis in blunt chest trauma. 7 Trauma 1971;11:129-45.

16. Bundy DW, Tilton DM. Delayed hemothorax after blunt trauma without rib fractures. Mil Med 2003;168:501-2.

17. Simon BJ, Chu Q, Emhoff TA, et al. Delayed hemothorax after blunt thoracic trauma: an uncommon entity with significant morbidity. 7 Trauma 1998; 45:673-6.

18. Misthos P, Kakaris S, Sepsas E, et al. A prospective analysis of occult pneumothorax, delayed pneumothorax and delayed hemothorax after minor blunt thoracic trauma. Eur 7 Cardiothorac Surg 2004;25:859-64.

19. Plourde M, Émond M, Lavoie A, et al. Cohort study on the prevalence and risk factors of late pulmonary complications in adults following a closed minor chest trauma [article in French]. C7EM 2013;15:337-44.

20. Émond M, Sirois MJ, Guimont C, et al. Functional impact of a minor thoracic injury: an investigation of age, delayed hemothorax, and rib fracture effects. Ann Surg 2015;262:1115-22.

21. Shields JF, Émond M, Guimont C, et al. Acute minor thoracic injuries: evaluation of practice and follow-up in the emergency department. Can Fam Physician 2010;56:e117-24.

22. von Elm E, Altman DG, Egger M, et al.; STROBE Initiative. The Strengthening the Reporting of Observational Studies in Epidemiology (STROBE) statement: guidelines for reporting observational studies. 7 Clin Epidemiol 2008;61:344-9.

23. Mangram AJ, Zhou N, Sohn J, et al. Pleural effusion following rib fractures in the elderly: Are we being aggressive enough? 7 Gerontol Geriatr Res 2016;5:341.

24. Skov T, Deddens J, Petersen MR, et al. Prevalence proportion ratios: estimation and hypothesis testing. Int 7 Epidemiol 1998;27:91-5.

25. Toll DB, Janssen KJ, Vergouwe Y, et al. Validation, updating and impact of clinical prediction rules: a review. 7 Clin Epidemiol 2008;61:1085-94.

26. Eagles D, Stiell IG, Clement CM, et al. International survey of emergency physicians' awareness and use of the Canadian Cervical-Spine Rule and the Canadian Computed Tomography Head Rule. Acad Emerg Med 2008;15:1256-61.

27. Stiell IG, Wells GA. Methodologic standards for the development of clinical decision rules in emergency medicine. Ann Emerg Med 1999;33:437-47.
28. Plourde M, Emond M, Lavoie A, et al. Cohort study on the prevalence and risk factors for delayed pulmonary complications in adults following minor blunt thoracic trauma. CFEM 2014;16:136-43.

29. Dobbin KK, Simon RM. Optimally splitting cases for training and testing high dimensional classifiers. BMC Med Genomics 2011;4:31.

30. Labarère J, Renaud B, Fine MJ. How to derive and validate clinical prediction models for use in intensive care medicine. Intensive Care Med 2014;40 513-27.

31. Laupacis A, Sekar N, Stiell IG. Clinical prediction rules. A review and suggested modifications of methodological standards. FAMA 1997;277:488-94.

32. McGinn TG, Guyatt GH, Wyer PC, et al. Users' guides to the medical literature: XXII: How to use articles about clinical decision rules. Evidence-Based Medicine Working Group. 7AMA 2000;284:79-84.

33. McLoughlin R, Mulcahy R, Kent P, et al. Haemothorax after rib fracture incidence, timing and prediction. Ir 7 Med Sci 1987;156:117-9.

34. Sharma OP, Hagler S, Oswanski MF. Prevalence of delayed hemothorax in blunt thoracic trauma. Am Surg 2005;71:481-6.

35. Holcomb JB, McMullin NR, Kozar RA, et al. Morbidity from rib fracture increases after age 45.7 Am Coll Surg 2003;196:549-55.

36. Bergeron E, Lavoie A, Clas D, et al. Elderly trauma patients with rib fractures are at greater risk of death and pneumonia. 7 Trauma 2003;54:478-85.

37. Eren S, Esme H, Sehitogullari A, et al. The risk factors and management of posttraumatic empyema in trauma patients. Injury 2008;39:44-9.

38. Karmy-Jones R, Holevar M, Sullivan RJ, et al. Residual hemothorax after chest tube placement correlates with increased risk of empyema following traumatic injury. Can Respir 7 2008;15:255-8

39. Wilson JM, Boren CH Jr, Peterson SR, et al. Traumatic hemothorax: Is decortication necessary? 7 Thorac Cardiovasc Surg 1979;77:489-95.

40. Meyer DM, Jessen ME, Wait MA, et al. Early evacuation of traumatic retained hemothoraces using thoracoscopy: a prospective, randomized trial. Ann Thorac Surg 1997;64:1396-400, discussion 400-1.

41. Knottenbelt JD, Van der Spuy JW. Traumatic haemothorax - experience of a protocol for rapid turnover in 1,845 cases. S Afr 7 Surg 1994;32:5-8.

42. Haggerty J, Pineault R, Beaulieu MD, et al. Continuité et accessibilité des soins de première ligne au Québec. Montréal: Centre hospitalier de l'Université de Montréal; 2004

43. Turk F, Kurt AB, Saglam S. Evaluation by ultrasound of traumatic rib fractures missed by radiography. Emerg Radiol 2010;17:473-7.

44. Steyerberg EW, Moons KG, van der Windt DA, et al. Prognosis Research Strategy (PROGRESS) 3: prognostic model research. PLoS Med 2013; 10:e1001381.

Affiliations: Centre hospitalier universitaire de Québec, Université Lava (Émond, Guimont, Plourde Moore, Kuimi, Boucher, Allain-Boulé, Le Sage); Université Laval (Émond, Guimont, Plourde, Boucher, AllainBoulé, Le Sage), Laval, Que.; Centre d'excellence sur le vieillissement de Québec (Émond, Boucher), Québec, Que.; Hôpital du Sacré-Coeur de Montréal (Chauny, Daoust); Département de médecine familiale et médecine d'urgence (Chauny, Daoust), Université de Montréal, Montréal, Que.; Centre hospitalier de Charles-LeMoyne (Bergeron, Vanier), Greenfield Park, Que.

Contributors: Marcel Émond had full access to all of the study data and takes responsibility for the integrity of the data and the accuracy of the data analysis. He was also responsible for the design and conduct of the study and for drafting the manuscript. Chantal Guimont, Jean-Marc Chauny, Raoul Daoust, Eric Bergeron, Laurent Vanier and Natalie Le Sage were responsible for recruitment at the 4 study sites. Chantal Guimont, JeanMarc Chauny, Raoul Daoust, Éric Bergeron, Laurent Vanier, Lynne Moore and Miville Plourde participated in conception and design of the study and the analyses. Batomen Kuimi analyzed the data. Valérie Boucher and Nadine Allain-Boulé contributed to analysis and interpretation of the data. Natalie Le Sage contributed to conception and design of the study and to data acquisition. All of the authors critically reviewed the manuscript and approved the final version for publication. All of the authors agreed to act as guarantors of the work.

Funding: This work was supported by a grant from Fonds de la Recherche en Santé du Québec (FRSQ 14056).

Acknowledgements: The authors are grateful to the emergency physicians and research assistants at the participating centres who recruited and followed the study participants.

Supplemental information: For reviewer comments and the original submission of this manuscript, please see www.cmajopen.ca/content/5/2/ E444/suppl/DC1 